\title{
CARACTERIZAÇÃO MORFOMÉTRICA DA SUB-BACIA DO RIO ESPINHARAS NO ESTADO DA PARAÍBA-PB
}

\author{
Jéssica Bruna Alves da Silva ${ }^{1 *}$, Simone Mirtes Araújo Duarte 1 \\ ${ }^{1}$ Departamento de Ciência Florestal, Universidade Federal Rural de Pernambuco,52171-900, Recife, Pernambuco.
}

*E-mail: jessica.bruna@ufrpe.br

\section{RESUMO}

O presente trabalho teve como objetivo realizar a análise morfométrtica da sub-bacia do Rio Espinharas, localizado no Estado da Paraíba. Para isso, foram gerados os Modelos de Elevação Digital (MDE) referentes à declividade e hipsometria. A área de drenagem calculada foi de $2942,0338 \mathrm{~km}^{2} \mathrm{com}$ um perímetro de $375677,3816 \mathrm{~km}$ e coeficiente de compacidade (Kc) 1,94 . O fator de forma (F) foi calculado em 0,68, com o índice de circularidade (IC) de 0,26, sendo classificada como sub-bacia de $3^{\mathrm{a}}$ ordem com densidade de drenagem $0,3317 \mathrm{~km} / \mathrm{km}^{2}$ e densidade de rede drenagem 0,000585 rios $/ \mathrm{km}^{2}$. Foi observado que o coeficiente de compacidade (acima de 1,50) associado ao índice de circularidade $(0,26)$, indicam que a sub-bacia não tende à forma circular, possuindo uma forma mais alongada que, em condições normais de precipitação, é pouco suscetível a enchentes, apesar do fator de forma $(0,68)$ apresentar um valor maior que o esperado. Desta forma, concluiu-se que a sub-bacia do Rio Espinharas não possui tendência a enchentes, porém, sempre é recomendado a utilização de práticas conservacionistas.

Palavras-chave: Morfometria. Drenagem. Escoamento Superficial. Manejo de Bacias.

\section{Introdução}

O estudo das áreas de bacias hidrográficas é de fundamental importância para o uso sustentável dos recursos naturais, visto que, diante de um processo de ocupação desordenada, resultante de um significativo aumento da população, da urbanização e do desmatamento da vegetação nativa para expansão de áreas agrícolas e pecuária, acarreta em graves e, muitas vezes, irreversíveis modificações ambientais na dinâmica natural dos ecossistemas [1-2].

Bacia hidrográfica é definida, segundo [3], como um conjunto de terras drenadas por um rio e seus afluentes, formada nas regiões mais altas do relevo por divisores de água, onde as águas das chuvas escoam superficialmente formando os riachos e rios ou infiltram no solo para formação de nascentes e do lençol freático. Em análises hidrológicas ou ambientais, uma das primeiras etapas realizadas é a caracterização morfométrica da bacia hidrográfica de interesse, visando explicar a dinâmica ambiental local. Ao se combinar os dados resultantes dessa análise, é possível obter indicadores físicos específicos, qualificando as alterações ambientais e diferenciando áreas aparentemente homogêneas [3]. Dessa forma, a área da bacia é essencial na definição da potencialidade hídrica e resposta hidrológica da mesma, uma vez que, quanto maior a sua área menos pronunciados serão os picos de enchentes, devido ao tempo prolongado necessário para contribuição da bacia, de uma só vez, a enchente [4].

As sub-bacias são as áreas de drenagem dos tributários do curso d'água principal. Diversos autores utilizam diferentes unidades de medida para definição da área. Para [5] classificamse como sub-bacia áreas maiores que $100 \mathrm{~km}^{2}$ e menores que 700 $\mathrm{km}^{2}$, enquanto para Rocha (1997) apud [6] são áreas entre 20.000 ha e 30.000 ha.

A sub-bacia do Rio Espinharas faz parte da Bacia Hidrográfica Piranhas-Açu, importante sistema da região do semi-árido nordestino, que está localizado no Estado da Paraíba e é imprescindível para o abastecimento humano e o desenvolvimento das atividades produtivas nos municípios de sua área de abrangência [7]. Dito isto, ressalta-se que, de acordo com [8] o manejo inadequado de sub-bacias nesta região pode desencadear sérios problemas, como alterações das respostas hidrológicas, erosão e redução da capacidade hidráulica dos reservatórios. Para tanto, faz-se necessário a geração de informações quantitativas consistentes, que aportem estudos qualitativos para um manejo adequado dessa sub-bacia.

Os subsídios para as tomadas de decisão dos gestores de recursos hídricos e atuações sociais com o meio ambiente são facilitados com o uso de softwares de processamento, como os Sistemas de Informação Geográfica (SIG). Abordado por 
diversos pesquisadores, o uso de SIG's auxiliam na determinação das características físicas de uma bacia hidrográfica, como a área, fator de forma e densidade de drenagem [9].

O SPRING é um SIG com funções de processamento de imagens, análise espacial, modelagem numérica de terreno e consulta a banco de dados espaciais, com o objetivo de construir um sistema de informações geográficas para aplicações em Gestão Geográfica, Florestas e Planejamento Urbano e Regional [10-11].

O presente trabalho teve como objetivo a análise morfométrica da sub-bacia do Rio Espinharas - PB.

\section{Metodologia}

\section{1 Área de Estudo}

A área da sub-bacia do Rio Espinharas, situada ao norte do estado da Paraíba, está circunscrita no retângulo limitado pelos paralelos $-7^{\circ} 31^{\prime} 12.35^{\prime \prime}$ e $-6^{\circ} 37^{\prime} 48.11^{\prime \prime}$, e pelos meridianos $-37^{\circ} 38^{\prime} 15.24^{\prime \prime}$ e $-36^{\circ} 34^{\prime} 43.62^{\prime \prime}$. A sub-bacia está inserida na bacia hidrográfica Piranhas-Açu, situada na região do semi-árido nordestino, com regime pluviométrico irregular e precipitações, geralmente, inferiores a $900 \mathrm{~mm}$. O bioma presente é a caatinga.

O Rio Espinharas é formado pela confluência do Rio da Cruz com o Rio da Farinha, que nascem nos municípios de Imaculada e Salgadinho, respectivamente, ambos no Estado da Paraíba.

\subsection{Processamento de Dados}

Foram realizados os downloads de arquivos Shapefiles disponíveis no Geoportal AESA-PB sendo estes extraídos para uma pasta e importadas para o software livre SPRING 5.4, onde foi criado o Banco de Dados "Espinharas" constando o limite da sub-bacia e sua drenagem. Também foram utilizadas imagens SRTM (Shuttle Radar Topography Mission) 30m x 30m, no formato Geotiff, disponibilizadas pelo INPE (Instituto Nacional de Pesquisas Espaciais), referentes à altitude. Após o processamento das imagens, foram criadas classes de hipsometria e o Modelo Digital de Elevação referente à declividade, o qual serviu como base para a criação das classes de declividade e geração de isolinhas.

\subsection{Caracterização Morfométrica da Sub-bacia}

\subsubsection{Coeficiente de Compacidade}

O coeficiente de compacidade $(\mathrm{Kc})$ foi calculado através da metodologia de [12], esse coeficiente é um número adimensional que varia com a forma da bacia, independente de seu tamanho. O coeficiente de compacidade (Kc) mostra a relação entre o perímetro da bacia e a circunferência de um círculo de área igual à da bacia.

Quanto mais o Kc de uma bacia estiver próximo da unidade, maior será sua suscetibilidade a enchentes. $\mathrm{O} \mathrm{Kc}$ foi determinado baseado na Equação:

$$
K c=0,28 * \frac{P}{\sqrt{A}}
$$

Onde: $\mathrm{P}=$ Perímetro da bacia $(\mathrm{m})$ e $\mathrm{A}=$ Área de drenagem $\left(\mathrm{m}^{2}\right)$

\subsubsection{Fator de Forma}

O Fator de forma relaciona a forma da bacia com a de um retângulo, correspondendo à razão entre a largura média e o comprimento axial da bacia. $\mathrm{O}$ cálculo foi realizado de acordo a metodologia de [12] e, segundo esses autores, uma bacia com um fator de forma baixo é menos sujeita a enchentes que outra de mesmo tamanho, porém com fator de forma maior. $\mathrm{O}$ fator de forma $(F)$ foi determinado, utilizando-se a Equação:

$$
F=\frac{A}{L^{2}}
$$

Onde: $\mathrm{A}=$ Área da drenagem $\left(\mathrm{m}^{2}\right)$ e $\mathrm{L}=$ Comprimento do eixo da bacia $(\mathrm{m})$

\subsection{3 Índice de Circularidade}

$\mathrm{O}$ índice de circularidade (Ic) tende a unidade à medida que a bacia se aproxima da forma circular e diminui ao passo que, a forma se torna alongada, assim como no Coeficiente de Compacidade. Para calcular o Ic, utilizou-se a Equação:

$$
I c=\frac{12,57 * A}{P^{2}}
$$

Onde: $\mathrm{A}=$ área da drenagem $\left(\mathrm{m}^{2}\right)$ e $\mathrm{P}=$ perímetro $(\mathrm{m})$

\subsubsection{Ordem dos Cursos d'água}

A ordem dos cursos d'água foi determinada de acordo com a metodologia de [13], na qual os canais sem tributários são classificados como canais de primeira ordem. Os canais de segunda ordem, por sua vez, são originados a partir da junção de dois canais de primeira ordem, podendo ter afluentes também de primeira ordem (Figura 1). 


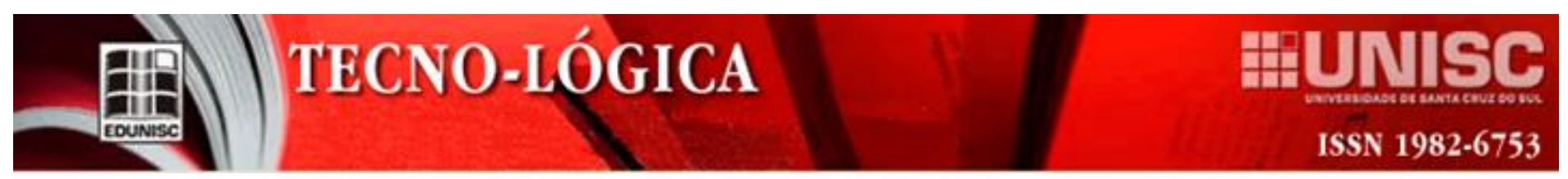

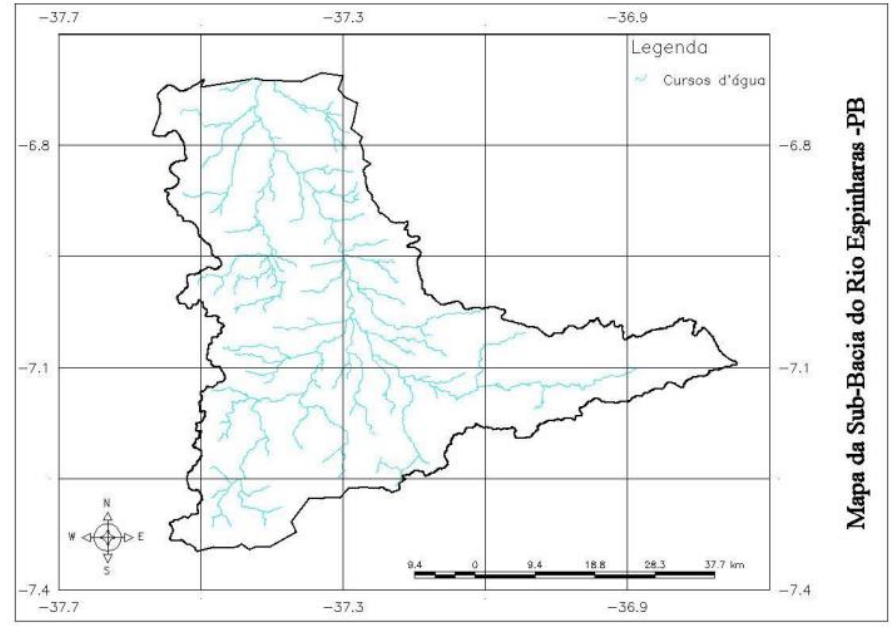

Figura 1 - Rede de Drenagem da Sub-bacia do Rio Espinharas.

\subsubsection{Densidade de Drenagem}

A densidade de drenagem (D) corresponde à relação entre o comprimento total dos cursos d'água (L) e a área de drenagem (A). Uma densidade de drenagem abaixo de $5 \mathrm{~km} / \mathrm{km}^{2}$ é considerada baixa; entre 5 e $13 \mathrm{~km} / \mathrm{km}^{2}$ é média; e acima de 13 $\mathrm{km} / \mathrm{km}^{2}$ é alta. A densidade de drenagem foi calculada através da Equação:

$$
D=\frac{L}{A}
$$

\subsubsection{Densidade da Rede de Drenagem}

A densidade da rede de drenagem (Dr) é relação entre o número de cursos d'água $(\mathrm{N})$ e a área da bacia (A), e foi calculada através da Equação:

$$
\operatorname{Dr}=\frac{N}{A}
$$

\subsection{Caracterização geográfica}

As distribuições de declividade e de hipsometria da área da sub-bacia foram analisadas através de imagens SRTM, processadas no SPRING e separadas em classes correspondentes a cada intervalo.

\section{Resultados e discussões}

A caracterização da sub-bacia do Rio Espinharas está apresentada no Tabela 1. A área calculada para a sub-bacia foi de $2942,0338 \mathrm{~m}^{2}$ e o perímetro calculado foi de $375677,3816 \mathrm{~m}$.
Tabela 1 - Características morfométricas da sub-bacia do Rio Espinharas.

\begin{tabular}{c|c}
\hline CARACTERÍSTICAS & RESULTADOS \\
\hline ÁSICAS & 2942,0338 \\
Perímetro da sub-bacia $\left(\mathrm{km}^{2}\right)$ & 375677,3816 \\
Coeficiente de compacidade & 1,94 \\
Fator de forma & 0,68 \\
Índice de circularidade & 0,26 \\
Ordem da sub-bacia & 3 \\
Densidade de drenagem $\left(\mathrm{km} / \mathrm{km}^{2}\right)$ & 0,3317 \\
Densidade da rede drenagem & 0,000585 \\
\hline (rios $\left./ \mathrm{km}^{2}\right)$ &
\end{tabular}

O Coeficiente de Compacidade da sub-bacia está bem acima de 1,50, mostrando que a mesma não possui tendência a enchentes, tal fato é reforçado pelo seu Índice de Circularidade, que possui o valor de 0,26 ; sendo uma sub-bacia alongada, onde inferem menor concentração de deflúvio e menor risco de enchente, [12] confirmam isso, ao afirmar que as bacias alongadas têm baixa acumulação do deflúvio e apresentam baixo risco de enchente nas condições normais de precipitação. Por outro lado, o Fator de Forma, diferente do que era esperado, ficou entre 0,50 e 0,75 , mostrando uma tendência mediana a enchentes.

Na Figura 2 observa-se a distribuição da declividade de acordo com a área da sub-bacia:

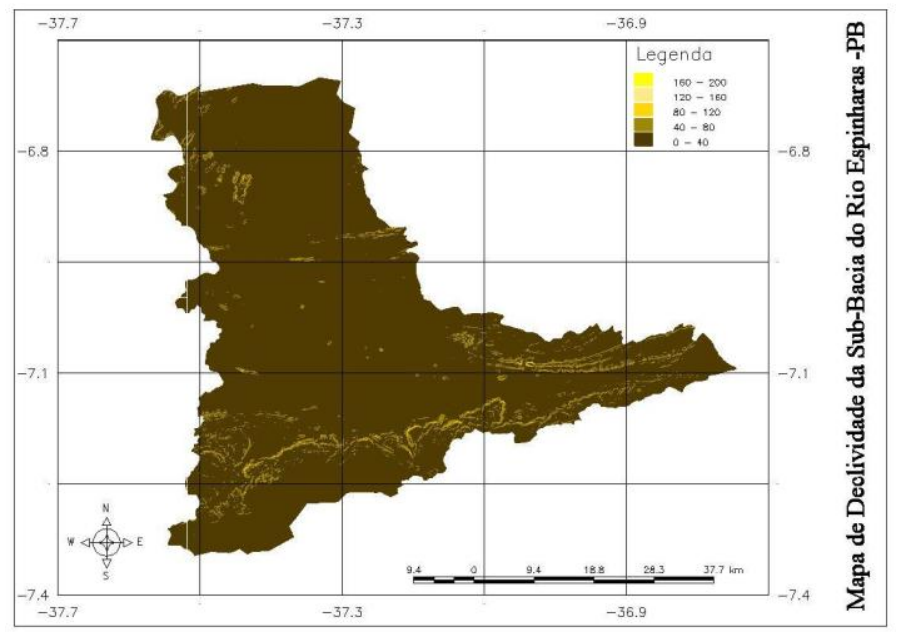

Figura 2 - Classes de declividade da sub-bacia do Rio Espinharas. 
Já na Tabela 2 é possível observar as áreas, em km, de cada classe e suas respectivas percentagens.

Tabela 2 - Classes de declividade: extensão e percentagem

\begin{tabular}{c|cc}
$\begin{array}{c}\text { CLASSES DE } \\
\text { DECLIVIDADE }\end{array}$ & ÁREA $(\mathbf{K m})$ & $\%$ \\
\hline $0-40$ & 2777,60 & 95,19343 \\
$40-80$ & 136,27 & 4,670179 \\
$80-120$ & 3,78 & 0,129704 \\
$120-160$ & 0,18 & 0,006095 \\
$160-200$ & 0,02 & 0,00059 \\
TOTAL & $\mathbf{2 9 1 7 , 8 5}$ & $\mathbf{1 0 0}$ \\
\hline
\end{tabular}

Na Figura 3 é possível observar a distribuição das altitudes de acordo com a área da sub-bacia.

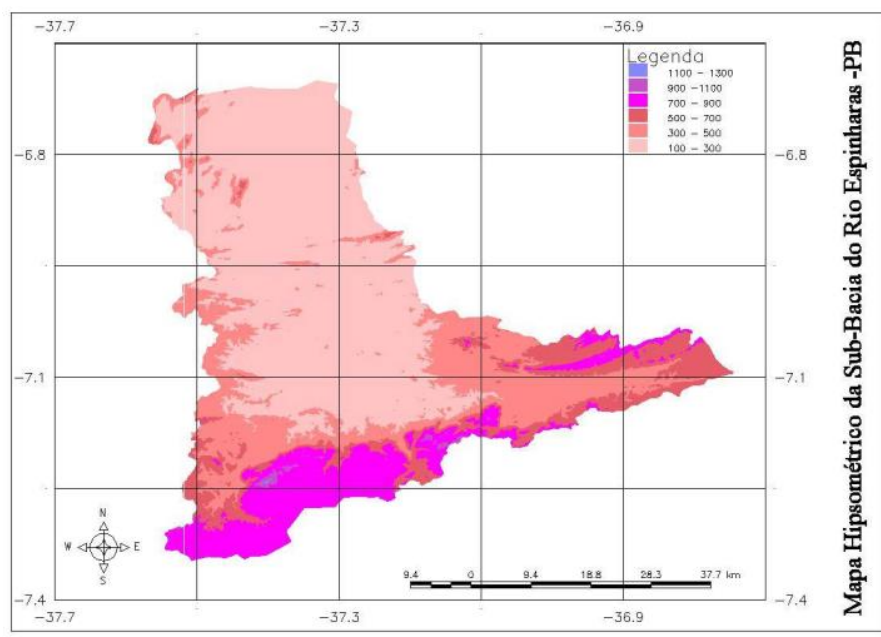

Figura 3 - Classes hipsométricas da sub-bacia do Rio Espinharas.

Já a Tabela 3 apresenta as áreas em km de cada classe e suas respectivas percentagens.

Tabela 3 - Classes Hipsométricas: extensão e percentagem

\begin{tabular}{lll}
\hline $\begin{array}{l}\text { CLASSES } \\
\text { HIPSOMETRICAS }\end{array}$ & $\begin{array}{l}\text { ÁREA } \\
(\text { Km) }\end{array}$ & $\%$ \\
\hline $100-300$ & 1544,6426 & 52,71003 \\
$300-500$ & 652,08247 & 22,25194 \\
$500-700$ & 337,837601 & 11,52851 \\
$700-900$ & 383,408066 & 13,08358 \\
$900-1100$ & 11,96943 & 0,40845 \\
TOTAL & - & 100 \\
\hline
\end{tabular}

O semiárido brasileiro possui características intrinsecamente relacionadas com à vegetação, o clima e o solo. De acordo com [14] a área onde a sub-bacia do Rio Espinharas está inserida a vegetação predominante é a Caatinga arbustiva arbórea aberta, que é constituída por uma vegetação rala com alguns indivíduos arbóreos e a presença de vegetação herbácea e cactácea, com alto grau de antropismo nas áreas de relevo plano.

O estudo ainda revela que a diminuição da vegetação tem provocado uma exposição direta do solo à ação da erosão, o que impossibilita a recuperação da vegetação nesta área e, consequentemente, interferindo na dinâmica da água na subbacia, tornando-se necessária a implementação de ações de conservação em médio e curto prazo para minimizar os possíveis problemas que possam decorrer do cenário avaliado.

A cobertura do solo é uma das práticas mais recomendadas para a região do semi-árido, favorecendo a infiltração, que proporciona um melhor aproveitamento da água da chuva e redução da perda de água por escoamento superficial [15-16].

\section{Conclusões}

A metodologia aplicada na delimitação da bacia, com auxílio do SIG SPRING e dados proveniente do SRTM, demostrou-se adequada e vantajosa quanto ao custo e aos benefícios, estabelecendo ainda uma padronização do traçado e posterior minimização de conflitos da unidade de gestão dos recursos ambientais.

Através da análise dos valores adquiridos nos cálculos realizados, é possível concluir que a sub-bacia do Rio Espinharas não possui tendência a enchentes no período chuvoso. No entanto, é sempre recomendado manter atenção a situação em que a mesma se encontra, realizando práticas que visem a conservação de seus recursos, que sofrem influência antrópica na alteração dos seus processos naturais, que pode desencadear enchentes, no período chuvoso, ou secas, no período de estiagem.

\section{MORPHOMETRIC CHARACTERIZATION OF THE RIO ESPINHARAS SUB-BASIN IN THE STATE OF PARAIBA-PB}

ABSTRACT: This paper aimed to perform the morphometric analysis of the Rio Espinharas sub-basin, located in Paraíba State. For this, the Digital Elevation Models (DEM) related to the slope and hypsometry were generated. The calculated drainage area was $2942.0338 \mathrm{~km}^{2}$ with a perimeter of $375677,3816 \mathrm{~km}$ and compactness coefficient $(\mathrm{Kc})$ 1.94. The form factor $(\mathrm{F})$ was 


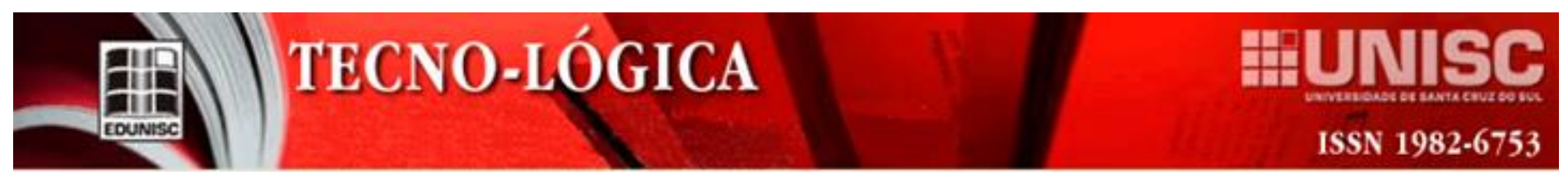

calculated at 0.68 , with the circularity index (CI) of 0.26 , being classified as 3rd order sub-basin with drainage density $0.3317 \mathrm{~km}$ $/ \mathrm{km}^{2}$ and net density. drainage 0.000585 rivers $/ \mathrm{km}^{2}$. In the results it was observed that the compactness coefficient (above $1.50)$ associated with the circularity index (0.26) indicates that the sub-basin does not tend to be circular, having a longer shape than under normal conditions. precipitation is unlikely to be flooded, although the form factor (0.68) is higher than expected. Thus, it was concluded that the Rio Espinharas sub-basin is not prone to flooding, however, the use of conservation practices is always recommended.

Keywords: Morphometry. Drainage. Runoff. Basin Management.

\section{Referências}

[1] VASCO, A. N. et al.. Avaliação espacial e temporal da qualidade da água na sub-bacia do rio Poxim, Sergipe, Brasil. Ambiente \& Água - An Interdisciplinary Journal of Applied Science. Taubaté, v. 6, n. 1, p. 118-130, 2011. Disponível em: <doi:10.4136/ambi-agua.178>. Acesso em novembro de 2019.

[2] SILVA, G. C. et al.. Caracterização Morfométrica da Bacia Hidrográfica do Riacho Rangel - Piauí, Brasil. Enciclopédia Biosfera. Centro Científico Conhecer - Goiânia, v.15 n.28; p. 244, 2018. Disponível em: $<10.18677 /$ EnciBio_2018B22>. Acesso em novembro de 2019.

[3] TEODORO, V.L.I.; TEIXEIRA, D.; COSTA, D.J.L.; FULLER, B.B. O conceito de bacia hidrográfica e a importância da caracterização morfométrica para o entendimento da dinâmica ambiental local. REVISTA UNIARA, n.20, 2007.

[4] TUCCI, C.E.M.. Controle de Enchentes, in: Tucci, C. (org). Hidrologia ciência e aplicação. Porto Alegre: Ed. da Universidade: ABRH cap 16, p621-658.: 952p. 1993.

[5] FAUSTINO, J. Planificación y gestión de manejo de cuencas. Turrialba: CATIE. 90p. 1996.

[6] MARTINS, F.B. et al. Zoneamento Ambiental da sub - bacia hidrográfica do Arroio Cadena, Santa Maria (RS). Estudo de caso. Cerne, Lavras, v.11, n.3, p.315-322, Jul./Set. 2005.

[7] PARAÍBA. Secretaria de Estado da Ciência e Tecnologia e do Meio Ambiente - SECTMA. PERH-PB: Plano estadual de recursos hídricos: Resumo executivo \& atlas/Governo do Estado da Paraíba; Secretaria de Estado da Ciência e Tecnologia e do Meio Ambiente, SECTMA; Agência Executiva de Gestão de Águas do Estado da Paraíba, Brasília: Consórcio TC/BR - Concremat, 2006. $112 \mathrm{p}$.

[8]ARAÚJO, J. C.; Guntner, A.; Bronstet, A. Loss of reservoir volume by sediment deposition and its impact on water availability in semiarid Brazil. Hydrological Sciences Journal, v.51, p.157-170, 2006. Disponível em: <https://doi.org/10.1623/hysj.51.1.157>. Acesso em novembro de 2019.

[9] DUARTE, C.C; GALVÍNCIO, J.D.; CORRÊA, A.C.B.; ARAÚJO, M.S.B. Análise fisiográfica da bacia hidrográfica do Rio Tapacurá - PE. Revista de Geografia. Recife: UFPE - DCG/NAPA, v.24, n.2, Mai/Ago. 2007.

[10] CAMARA, G.; SOUZA, R. C. M.; FREITAS, U. M.. SPRING: Integrating remote sensingand GIS by object-oriented data modeling. Garrido J Computers\&Graphics, 20: (3) 395-403, May-Jun. 1996.
[11] SPRING. Manual do Spring. 2006. Disponível em: <http://www.dpi.inpe.br/spring/portugues/tutorial/index.html>. Acesso em julho de 2019.

[12] VILLELA, S.M.; MATTOS, A. Hidrologia aplicada. São Paulo: McGrawHill do Brasil. 245p. 1975.

[13] STRAHLER, A.N. Quantitative analysis of watershed geomorphology. New Halen: Transactions: American Geophysical Union. v.38. p. 913-920. 1957.

[14] SILVA, R. M. P.; LIMA, J. L.; MENDONÇA, I. F. C.. Alteração da cobertura vegetal na Sub-Bacia do Rio Espinharas de 2000 a 2010. Revista Brasileira de Engenharia Agrícola e Ambiental. Campina Grande, v.18, n.2, p.202-209, 2014. Disponível em: <http://dx.doi.org/10.1590/S141543662014000200011>. Acesso em novembro de 2019.

[15] BORGES, T. K. S. et al.. Influência de práticas conservacionistas na umidade do solo e no cultivo do milho (Zea mays L.) em semiárido nordestino. Revista Brasileira de Ciência do Solo. Viçosa, v.38, n.6, Nov./Dez. 2014. Disponível em: <http://dx.doi.org/10.1590/S0100-06832014000600021〉. Acesso em novembro de 2019.

[16] SILVA, M. A. et al.. Sistemas de manejo em plantios florestais de eucalipto e perdas de solo e água na região do Vale do Rio Doce, MG. Ciência Florestal. Santa Maria, v. 21, n.4, Out./Dez. 2011. Disponível em: <http://dx.doi.org/10.5902/198050984520>. Acesso em novembro de 2019. 